\title{
PROFESSIONALISM
}

ISSN: 1893-1049

Volume 10 , No 3 (2020), e3906

https://doi.org/10.7577/pp.3906

\section{Community-led Work and Its Impact on Deprofessionalization: The Case of Public Library Professionals}

\author{
Jenny Nilsson \\ Linnaeus University, Sweden
}

Contact: Jenny Nilsson, Sweden, jennysnilsson94@gmail.com

\section{Abstract}

The objective of this empirical study was to explore the impact of community-led work on the (de-)professionalization process among public library professionals in Canada through the analyzation of transcripts from 11 semi-structured interviews and a guideline document. The results were analyzed and sensitized through Abbott's professionalization theory (1988) and Bourdieu's praxeology theory $(1986 ; 1992)$. With the methodology of grounded theorization, the study found that the profession has changed, and is changing, into the direction of possible deprofessionalization, due to not only external but also internal factors in the form of a collegial conflict.

\section{Keywords}

Canada, public library profession, librarians, professionalization, deprofessionalization, community-led, community relationship, collegial conflict

\section{An internal divide}

The community-led approach has been popularized among a wide spread of professions over the course of the past decades in sectors extending from health care and social work to librarianship (Athena, 2016; Nichols, Knighton, Brunisholz, Elbel, Smith, Choberka, Belnap, Allen, Moore \& Srivastava, 2020; Williment, 2009; ;). The practice involves centering the (C) 2020 the authors. License: https://creativecommons.org/licenses/by/4.0/ (CC-BY 4.0) 
needs of clients, patrons, or the community by inquiring and involving them in the development of the service that the professionals provide. In this study, with the case of a group of public library professionals in Canada who (mainly) practices the community-led approach, the impact of this practice on the profession itself will be explored.

By the end of the 20th century and in the beginning of the 21st century, the increased internet access among the public changed the demand of library services and thereby the professionals' work activities. A contemporary example of the consequences of these changes is the fact that several public libraries in Canada were under threat to be closed in 2018 , although they remained open but underfunded (CBC, 2018). What can be detected as a reaction to these changes is the initiatives of increased community involvement throughout Canada in the past decades which has been described as an adjustment to meet the needs of the patrons and remain relevant (The Working Together Project, 2008, p. 7). The community led movement within the public library profession is an example of this, and it has taken the form of for example community reach out, where the librarians engage and adjust their programs and resources to non-users of the library (Kripps \& Middlemass, 2018). In the academic field, courses regarding the community led approach have also been taught in Nova Scotia in recent years (Dalhousie University, 2020).

From this perspective, the relationship between patrons and public library professionals seems to have changed-the professionals' only or main tasks does no longer seem to be to provide books and references. These old work activities were the cornerstones of the professionalization process that the occupation went through originally through academic institutionalization. This disparity indicates that there is a movement within the public library profession that is more concerned with relationship-building work activities and less concerned with the traditional work activities. This possible divergence among public library professionals will be explored in this study through the experiences of professionals who are, mostly, working with the community led approach as well as through analysis of a guideline document. Through identifying the impact of community-led work on the (de)professionalization process within this professional group, a deeper understanding of the profession as well as these processes, may emerge.

This study is limited to exploring the experiences of Canadian public library professionals operating primarily within medium sized cities, mainly practicing the community-led approach. The changed work activities within the profession, found in previous studies, calls for a sufficient theorizing of the (de-)professionalization process of this group. The objective of this study is therefore to answer the following research question: What is the impact of community-led work on the (de-)professionalization process among public library professionals in Canada? 


\section{Changed dynamics challenging the profession}

Results from previous studies indicate that the public library profession was professionalized through mechanisms such as abstract knowledge (Abbott, 1988) and that there currently is a crisis within the field of librarianship (Dorner, Campell-Meier \& Seto, 2017). The studies have concluded that this crisis stems from the digital revolution as it challenged the need of libraries-and therefore librarians - in society. Researchers have found that specific competencies are needed in order to stay relevant, or to develop the librarian profession, and key competencies beyond what is being taught in the library schools have been identified (Hansson \& Wisselgren, 2018; Shumaker, 2012; Tîrziman, 2017).

The librarians Berthoud and Finn (2019) discussed and emphasized the importance of having a social justice mentality in the daily practice of their profession. Through semi-structured interviews and participatory observation, Hyder and Tissot (2012) found that as terminology has a real effect on marginalization, discourse is an important aspect to consider when institutions, such as public libraries, aim to pursue an inclusive practice. Williment (2009) presented a paper where a general evaluation of the Community-Led Service Planning Model, in Canada, was presented as a way to practice social inclusivity at public libraries. The study concluded that the approach to co-create activities resulted in more relevant library services. Another paper on the topic was written by Williment and Jones-Grant (2012) discussing asset mapping. The approach entails identification of current resources within the community in order for the public library to complement these services. Over the course of a decade, Delica and Elbeshausen (2013) studied community participation in Danish at-risk neighborhoods through interviews, field observation and participation. They found that increased community participation and centers based on social needs among minority groups in at-risk-communities were benefitting these groups. These studies indicate a strive among (some) professionals to work differently than before. As this changed approach might be translated into changed work activities, this will be analyzed in this study in order theoretically explore what this change can mean for the (de)professionalization process among the professionals.

The mechanisms found through studies regarding other professions, such as sensemaking of professional identity within the welfare sector (Harrits, 2016), effects from co-creating as professionals with the community within the health field (Kirkegaards \& Andersen, 2018) as well as the analysis of which professional groups might be most open to co-production among mental health professionals (Leemeijer \& Trappenburg, 2016) may be generative in the exploration of the (de-)professionalization process. Through exploring the possibly changed relation between the professionals and the community they serve-its internal impact as well as the process may be further understood.

No previous studies explore the current (de-)professionalization process of public library professionals, what has been concluded is rather that the profession is facing a challenge or 
crisis and strategies for how this can be managed. The essence of this crisis is found to be affected by external factors, namely the digital revolution and funding cuts, however no internal factors have been delineated. This study will focus on how the professionals are reacting to, and perhaps are contributing to, the changes internally by exploring the impact of community-led work on the (de-)professionalization process. This study brings a new perspective, by exploring these changes through the lens of sociological theories of professions. Since professionalization, according to Abbott's theory, is a process that requires external validation but also internal strengths-exploring these aspects of the profession may be fruitful in order to theorize this impact. Through the lens of Bourdieu's praxeology theory, these internal factors may be further conceptualized and specified.

\section{Theorizing (de-)professionalization}

The theoretical framework of this study consists of Abbotts professionalization theory, Bourdieu's praxeology theory and my own sensitized concepts. Through Abbott's theory of how the professionalization process works, the crisis of the public library profession found in previous studies, will be explored. What Bourdieu's perspective adds to this theory is a conceptualization of the mechanisms of socialization and reproduction that one could argue, enable the professionalization process. My own sensitizing of Bourdieu's doxa, will be used to further theorize the different ideas among the professionals, enabling for a theorization of the internal impact of community-led work.

\section{Abstract knowledge and control over work activities}

According to Abbotts (1988) professionalization theory, analysis of professionals' work activities is essential to understand this process. Abbott found abstract knowledge to be an instrument that professionals use to legitimize their professional status and autonomy over a specific set of work activities. However, the purpose or use of this is more symbolically charged than practically charged. This is because the abstract knowledge works as a legitimizing tool of professional work by "clarifying its foundations and tracing them to major cultural values" which can be used to "legitimize that work in the context of larger values". However, Abbott (1988, p. 59) acknowledged that these activities might only, in fact, be loosely related to the work that the professionals actually perform ${ }^{1}$. In relation to the changed work activities among library professionals, Abbott's perspective will be used to explore how abstract knowledge operates within a changing profession.

Abbott also suggested that professionalization, or deprofessionalization, is a multidirectional process, meaning that different tasks within a professional's schedule may

\footnotetext{
${ }^{1}$ According to Carlhed (2011), one of the parallels between Bourdieu and Abbott is their acknowledgement of the difference between practical and "educated" knowledge. However, since Abbott's concept is further developed specifically for studies of professions, I chose to work primarily with this conceptualization.
} 
be more central than others. By exploring which activities that are core, and which that are in the periphery, a clearer view of what the professionals actually do and the impact of community-led work on the (de-)professionalization process may emerge. According to Abbott's theory, when an occupational group controls their work activities, meaning that they are the only profession having those work activities, they can get professionalized. The group usually need to compete with other occupational groups to achieve or maintain control over these work activities. The absence of control over a certain set of work activities can be a part of the deprofessionalization process according to the theory (Abbott, 1988 , p. 60-61; p. 82-83).

\section{The doxa's challengers, enablers, and loyalty culture}

One of the main ideas of Bourdieu's praxeology theory is the doxa-the natural order. The concept concerns power in the sense that it represents "norms and beliefs" through stating what is right and what is wrong-what is natural and what is unnatural. This concept demonstrates the idea of an abstract "law enforcement" since we follow these norms as though they are rules-often oblivious to the fact that they are created through social interactions. Bourdieu meant that establishment-in combination with a high concentration of control and structure-can generate a conflict between conservative forces and challenging forces. Loyalty is a response to the gift that is the individual's benefits, or perceived benefits, of the doxa (Bourdieu, 1986, p. 471). The more consecrated the individual or group is-meaning the more dedicated they are to enable the doxa-the more willing they are to consecrate objects within the doxa as well as reproduce its actions (Bourdieu, 1992, p. 159).

Figure 1: Field of opinion and doxa

Figure A :

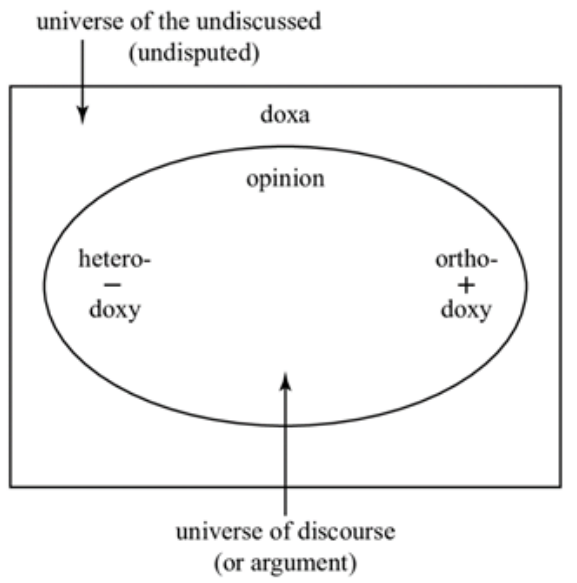

Figure B:

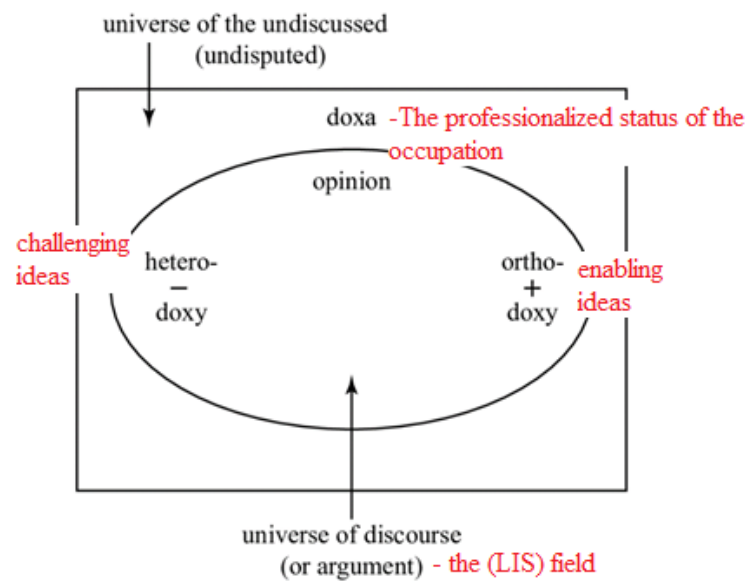

Illustration of Bourdieu's field of opinion and doxa is found in figure A (Bourdieu, 1977, $p$. 168) while my sensitized version of the theory is found in figure $B$. As illustrated in figure $B$, 
the doxa is understood as the professionalized status of the occupation and the universe of discourse is understood as the Library and Information Science (LIS) field. The sensitized concept 'challenging ideas' is placed next to the heterodoxy part of the doxa while the other sensitized concept 'enabling ideas' is placed next to the orthodoxy part of the doxa.

In the analysis, the concept of the doxa will be further understood through my own sensitized concepts-challenging and enabling ideas-meaning the ideas that the professionals express or possibly embodies, illustrated in Figure B. I name the sensitizing of the conservative forces as enabling ideas and the challenging forces as challenging ideas to deepen the understanding of the professionals' experiences. Identification of these ideas enables for a deeper analysis of what it specifically means to challenge or enable the doxa within the public library profession. It is my argument that, solely distinguishing that there are different forces within the doxa does not give enough space to theorize what ideas are affecting these forces and exactly how. My argument is that the concept of forces heuristically sends focus to opposites - negative or positive forces-but lacks the heuristic focus towards what these positives and negatives actually entails in specific fields or social rooms. Challenging and enabling ideas will be utilized as a tool to not only distinguish between different forces among public library professionals but also to explore further what they may entail.

In regard to professions that are undergoing changes, the concept of the doxa offers a perspective regarding why a conflict can be created between the professionals who are open to change and those who are opposed to it. Education, which is a crucial step in the professionalization process according to Abbott (1988), "has an ideological function", as it operates as an indoctrination to the specific logic and doxa of that field. Education works as a social reproduction tool (Bourdieu \& Passeron, 2008, p. 151)-which according to my conceptualization is reproduced by the embodiment of enabling ideas.

\section{Method and Methodology}

\section{Data collection}

The data consisted of transcripts from 11 semi-structured interviews with librarians, conducted between the 6th and 24th of December in 2019, and a national public library position statement. Through the interviews, the librarians daily work life could be explored as well as mechanisms affecting the (de-)professionalization process. Semi-structured interviews enable for a greater knowledge-producing potential than structured interviews according to Brinkmann (2013, p. 21) due to the possibility to adjust the interview to different angles that the interviewee deems as important. Privacy of the interviewees was ensured through anonymization and randomized quotations. Informed consent was obtained from all participants before the interviews. The document that was analyzed was the Position Statement on Diversity and Inclusion by the Canadian Library Association (CLA, 
2012) which is a statement utilized by all public libraries in Canada. This statement presents goals and ethical values of Canadian public libraries and is therefore relevant in order to further understand the discourse of the LIS field.

\section{The sample}

The interviewees operated in three midsized cities and one large city, located in three different provinces of Canada -in Nova Scotia, Ontario, and British Columbia. I interviewed five Community Librarians, one Newcomers Librarian and three library managers. The managers were working in the departments of programming and community, research and analytics and service design. The two other interviewees worked as a Chief librarian and the other as branch head. The average interviewee had worked as a librarian since 2005 whereas the most experienced professional had worked since 1978 and the least experienced professional had worked since 2017. The geographical spread in combination with the variating years of work experience, contributed to a more diverse sample.

I was dependent on gaining access to senior staff members to get in contact with librarians at different branches. Due to this, initial convenience sampling, turning into snowball sampling was practiced. In search for a more diverse group of interviewees, librarians were also contacted through emails that were sent to 20 public libraries throughout 10 Canadian provinces, geographically distributed to increase the generalization capacity of the data. However, most of the interviewees were found through snowball sampling, as only one professional outside of the referring - system was available for an interview within the timeframe of the study. Five out of the eleven interviewees had also worked together on a project called "The Working Together Project" 2.

No data was available concerning how many public library professionals operate within Canada today. The latest statistics was reported in 2012, when the number was 2,796 (CLA, 2012 , p. 6). The more recent statistics does not differentiate between different librarians (for example academic, public etc.), but illustrates that there were 16,700 librarians in Canada in total in 2018 (Government of Canada, 2018). It is difficult to determine the representability of a sample without a clear population number, however, these statistics may illustrate in which ratio the population may be. Regardless, whether the sample was representable of the professional group as a whole is doubtful concerning that the majority of the interviewees were practicing the community-led approach - which was found to be a contributor to a collegial conflict within the profession. However, theorization concerning different ideas emerged as important information about the collegial conflict among the public library professionals. This may indicate that the sample of this study may possibly be

2 A governmentally funded project in Canada during 2004-2008 where selected public libraries were working with the community-led approach (Working Together Project, 2008). 
representative of the professionals who practice the community-led approach, although population data is needed to determine if so, and to what extent.

The sample size was determined based on theoretical sufficiency (Dey, 1999, p. 257), meaning that the sample was deemed sufficient when no new information challenged the categories that had already been coded from the already collected interview data. A consensus was reached through the categorization of data by the 11th interview. The ability to reach theoretical sufficiency by such a small sample may be further understood by the limited ratio of librarians in Canada-especially those who practice the community-led method. The interviews were also in depth and on average 50 minutes long, which enabled for a rich data set to theorize. Smaller samples may also be deemed acceptable for studies that does not evoke scepticism through claims concerning, for instance, "contradict[ions of] established research" according to Charmaz (2006, p. 114). This is in alignment with this study as it found a change within the public library profession - in accordance with the academic discourse concerning this change, or crisis, found in previous studies.

\section{Coding of data}

Since this was a grounded theory study, the theorization process was inductive (Charmaz, 2006). Through theorization of the data, this study generated hypothesis in relation to the research question. This method involves the core principles of "(1) questioning rather than measuring, and (2) generating hypotheses using theoretical coding" (Auerbach and Silverstein, 2003, p. 16). Through the use of NVivo Software as a tool in the analysis process, the data was digitally transcribed, organized and coded.

Repeating ideas were detected in the material and consisted mainly of the professionals' aim to meet the needs of the community, to build and maintain relationships with the community and their experiences with expertise attitudes. After I organized the repeated ideas, a theme emerged in the form of a conflict within the public library profession regarding how it should be practiced and what should be taught in library schools. The next step in the coding process was to organize the themes into "larger, more abstract ideas" (Auerbach and Silverstein, 2003, p. 42) and through the lens of Abbott's professionalization theory, complemented by concepts from Bourdieu's praxeology theory and my own sensitized concepts, a conflict was coded between different ideas within the doxa of the profession. The social mechanisms of the professionalized nature of the occupation, in combination with the socializing mechanisms, constructed the embodiment of professionals who use enabling or challenging ideas of the doxa-essentially affecting the professionalization process. The document analysis was coded through incident-by-incident coding. This means that the different sub-statements, were coded individually (Charmaz, 2006, p. 51). Two of these statements were coded as challenging ideas of the doxa. 


\section{Results and Analysis}

\section{Contrasting abstract and practical knowledge}

According to Abbott's professionalization theory, the process is built on legitimizing institutional processes such as academic degrees. Since a master's degree in LIS is a requirement for librarians in Canada (NOC, 2020), the competencies the professionals have acquired through their education as well as through work experience, will be explored through the analysis.

When asking about the different competencies or skills that they had developed through library school, I was met with surprise and even laughter on occasion:

"[laughing] Oh, you see, a lot of the competencies that they taught in library school I'm not sure if.. I'm not sure if they're applicable" - Librarian 1

"I haven't thought of that in years, and now that I think of it, I must say that I haven't used much of the skills I learned during my education..." - Librarian 6

It appeared to be a topic that some of the interviewees seemed to have given a lot of thought, while others seemed to reflect more intuitively. Through this data, an experienced contrast between their education and their profession can be detected. The observed emotionally charged reactions can be detected as indicators of how strongly these librarians felt about the apparent divide between these two spaces. Frustration was coded as a main emotion among the librarians as they reflected on their experiences.

Some managers also expressed concern over the staff that they are training since there appear to be a different idea of the profession within the educational space versus the occupational space. One manager shared the difficulty of training new staff - who technically are academically qualified:

"There's two questions what do they and what should they develop. [...] Public library is like a specialty within the degree so it's easy to get a library information degree with no exposure to libraries." - Librarian 2

The fact that it is possible to be academically qualified to work as a public library professional without taking any courses regarding public libraries (Government of Canada, 2020), demonstrates a clear gap between what is being taught in library school in contrast to the skills that the librarians needed to do their work.

The most frequently mentioned, or similarly phrased, competencies within the educational versus the occupational space, mentioned by at least 6 out of 11 interviewees, are presented in the table below. 
Community-led Work and Its Impact on Deprofessionalization

Table 1: Table of competencies that were mentioned or phrased similarly by at least six of the eleven interviewees.

\begin{tabular}{|l|l|l|l|}
\hline Library school & Frequency & Work experience & Frequency \\
\hline Collection building & 11 & Relationship building & 9 \\
\hline Program developement & 8 & Listening skills & 9 \\
\hline Intellectual freedom & 6 & Service minded & 8 \\
\hline Ethics & 6 & Conflict resolution & 7 \\
\hline & & Humility & 6 \\
\hline
\end{tabular}

As illustrated through the table above, the most frequently mentioned competencies developed within the educational space were collection building (11), followed by program development (8), intellectual freedom (6) and lastly ethics (6). The most frequently mentioned competencies developed through work experience were relationship building (9), listening skills (9), the ability to be service minded (8), conflict resolution (7) and lastly, humility (6). The interviewees generally mentioned more competencies that they had developed through work experience, however, it is to be noted that the mentioned competencies from work experiences may intersect. This data rather shows the different focuses of the spaces-where the work experience-based competencies were coded as more relationship-oriented.

In order to further demonstrate the discourse surrounding these competencies, and the spaces in which they are acquired, excerpts from the interviews where the librarians answered the question of what competencies they believe are necessary in order to do their work are presented below:

"Dealing with conflicts because for example homeless people are very stressed because their lives are very difficult and complex and they have short time spans, like one hour, that can affect their behavior, they're in this permanent anxiety condition.[...] You need the skills as a library worker [so] that you can deescalate situations, you can manage conflict in a good way. We don't want to throw anyone out [...] But we must handle the behavior because it can be disturbing for other patrons and other staff." - Librarian 5 
"Listening to patrons and understanding what their questions are, talking to people from all different walks of life and finding common ground are some of the main [skills]" - librarian 3

"We're really trying to position ourselves in the community as a space for people that live in it so it's really important to us to be mindful of our relationships" Librarian 6

The interviewees exemplified under what circumstances, or in which situations, that these competencies are necessary. The excerpts above specifically concern the competencies regarding interpersonal relationships. Through the data, the community, or the patrons, were detected as important components since the professionals expressed that they needed these skills to have and uphold a good relationship with them. Maintaining the relationships through listening, finding out what the community needs from the library and the ability to resolve conflicts were coded as indicative factors of the nature of these competencies. These skills differ from the more practical skills that the librarians learnt in library school according to the data.

A gap between what is being taught and what is being practiced within a profession can be analyzed through Abbott's concept abstract knowledge. Abstract knowledge is a legitimizing form of knowledge used through institutions such as academic education to control the professionalization process. This knowledge is noted to not often relate to the practical knowledge used within the profession. One could argue that the competencies that are being taught at library schools in Canada are consisting, to some degree, of abstract knowledge since the skills that the librarians acquired through working differed in their nature. The abstract knowledge can be viewed as more practical in terms of using and developing systems while the practical knowledge can be viewed as more relationship oriented. Through the theorization of this data, a gap between abstract and practical knowledge can be detected as a key element in what appears to be a conflict between the educational body of the LIS field and the public library profession. This conflict is coded as a part of the essence of the profession's contemporary status.

\section{The essence of the conflict}

According to Abbott's professionalization theory, professions are founded on a major cultural value. This value, in combination with my own sensitized concepts challenging and enabling ideas of the doxa, will act as guides through the exploration of this conflict.

The frustrated emotions in combination with the gap between the abstract and practical knowledge of the profession theorized in the previous section, were detected as indicators of a conflict. When the professionals shared how they view their profession in regards to competencies taught in library school, a majority of them shared that they find it problematic that they as professionals are taught to view themselves as automatic experts, 
even on other peoples' lives. The following data excerpts illustrates some of the experiences that they had.

"In library schools there's a lot of discussion around expertise and that's how the profession tried to sell itself because 'we're experts'" - Librarian 4

"We always say that the community is an expert on its own needs" - Librarian 7

"Most librarians tend to be, in my experience, white, from middleclass backgrounds, educated, and they have this, what I call, professional mindset which basically means 'I'm well educated, I've been to library school, I know what I'm doing, I'm very competent and I'm basically the expert' and the issue with that is [that] with community led work you're not the expert - the community knows their needs better than you do because they've lived the experience [...] So it's a bit of a challenge for some professionals to kind of give up that power, give up that status and give up that we can never assume what people's needs are." - Librarian 8

The interviewees shared how they were taught from library school to view themselves as experts. Contrasting ideas to this notion was found among several librarians who shared that they view the expertise to be found in the community instead. The interview excerpts above demonstrate that the experience from library school have been (for several of the interviewees) that the doxa conditioned them into believing that as librarians - they are experts. By acknowledging the source of this "mindset", coded as the doxa, the librarians acknowledged the strength of this culture. The strength of the culture that creates these enabling ideas can be understood through the socialization process. The doxa has been challenged by the challenging ideas through the core idea of the community being an expert on its own needs. The concept can be further understood through the very academic institutionalization that professionalized librarians - Bourdieu argued that education is one of the most powerful socialization processes. Another aspect that strengthens this theory is Bourdieu's concept culture of loyalty where the professionals gain a sense of obligation due to the institutional legitimization that gained them their position as professionals. This may explain why some librarians are opposing change within their profession.

Another interviewee emphasized the importance of the non-expert "attitude":

"If you have this [expert] attitude in the community, you can actually kill relationships" - Librarian 10

The phrasing of risking to kill relationships empathizes the importance of the relationship between the community and the librarians. This further supports the narrative of certain librarians being more relationship oriented and valuing relationships with the community and believing that they are fundamental for the occupation. 
Expertise was coded as an essential aspect of the public library profession-whether it is in the form of a challenged or enabled idea. Expertise was also found to be a major cultural value, embodying the foundation of the professionalization of the profession. According to Abbott, the core of professionalization is expertise - this problematized the conflict since the challenging ideas within the doxa might essentially oppose the professionalized status since they are opposing the expertise narrative of their field.

\section{Lack of competitiveness}

Autonomy over a certain set of work activities is considered a crucial aspect of the professionalization process according to Abbott's theory. It is therefore necessary to explore the professionals' control, or lack thereof, concerning work activities. Through the analyzation of interview data regarding the work activities of the profession, this will be theoretically explored.

The tasks of managers and librarians differed slightly since managers spent more time in meetings, planning and staff training. Activities mentioned by at least eight of the interviewees were however collection building, community engagement and program development. What could be detected from the data was activities taking place outside of the library and specifically with the purpose of engaging with the community. This was done through what the professionals' referred to as community outreach or community engagement.

The librarians exemplified how their branches have operated to meet the needs of homeless people and other socially vulnerable groups, both outside and inside of the library. An excerpt of this data is presented below:

"The library would hand out free bus tickets so [they] could go to other organizations where they could access clothes and so on" - Librarian 2

"In terms of where they can go during the day the library is the main place, we are warm, we don't throw people out. They will be moved from shopping centers when not buying anything. We meet that basic needs during the day by having them in the building. Some have medical needs, so we bring in street nurses and they can check, we try to bring the services into the library to meet their needs rather than sending them back out into the community where they don't feel safe. Many homeless people say that they feel that the library is the safest place in town. Because even [the shelters] are pretty violent places, libraries [are] a sanctuary in a way." Librarian 5

Through offering free bus tickets and having medical services operating inside of the library, the professionals practiced work activities that are not explicitly mentioned in the national description of their work activities (NOC, 2020). By stating that they "meet their [homeless 
peoples'] basic needs during the day", the librarian indicated that they view it as a part of their profession to meet the needs of the community in collaboration with other actors. The labeling of the library as a sanctuary for some societal groups, was coded as a challenging idea, embodying the relationship-oriented view of work.

Relationship-oriented work activities are not very well aligned with the National Occupational Classification (NOC), they are however more in alignment with the excerpt from the Position Statement on Diversity and Inclusion by the Canadian Library Association (CLA, 2012), presented below:

[A] diverse and pluralistic society is central to our country's identity. Libraries have a responsibility to contribute to a culture that recognizes diversity and fosters social inclusion.

Libraries strive to deliver inclusive service. Canada's libraries recognize and energetically affirm the dignity of those they serve, regardless of heritage, education, beliefs, race, religion, gender, age, sexual orientation, gender identity, physical or mental capabilities, or income.

The statement encourages libraries to deliver inclusive services and to "recognize and energetically affirm the dignity of those they serve". This was theorized as a challenging idea of the doxa. According to Bourdieu's theory of the doxa - this very act challenges the doxa if we define it as what is socially accepted as the "natural" work of librarians. All social fields have a set of believes and norms that create a framework of what is right and wrong within it-this constitutes the doxa. The conflict, in regard to Bourdieu's theory, could only be created within a context that had been established for some time, meaning that it had a history where a high concentration of control and structure had been practiced. Due to the professionalization of the librarian profession, this context shows just that - a strong structure that is currently being questioned by some of its members.

The librarians appeared to view themselves as professionals who are not only supposed to follow the work activities specified in the Canadian job description, but also to do something more. It appeared to not only be something that they wanted to incorporate as a part of the work of the library - but also something that naturally should be a part of the occupation according to them. Several interviewees referred to, or even showed me, Maslow's hierarchy of needs and demonstrated how the pyramid works in relation to the librarians:

"[...] So you can't do the stuff up there until you address those basic human needs"Librarian 1

"We need to [...]help them [homeless people] get accommodation, help them get a job so that we can move on to more high level needs such as becoming a library member, using the library, learn more about the collection, attending programs. 
They're not gonna do that when they don't know where their next meal is coming from. So, we start at the bottom with the basic needs and then we move further and further up on the Maslow's triangle." - Librarian 3

What can be identified through this data is a pattern of the professionals catering to specific groups, with the aim to provide them with, or redirect them to other actors, where they essentially can get further integrated in society. Eight of the librarians explained how they viewed it as their mission to guide groups, and individuals, in society up to the top - selffulfillment. This meant that they regarded it as their professional duty to, through cooperation with organizations in the community as well as the community itself, aid these groups even at the lowest level with needs such as shelter and food.

Two public library managers shared how these relationship-oriented activities in the profession have been met by their colleagues and employees:

"Not everything we did in the past is relevant anymore and that was another tough call for staff. So we said to staff we need to stop doing that thing even though it's something you really like doing or you're really good at. And we now need to do this thing over here instead, because that thing you were doing in the past no longer addresses the issues that we're engaged in" - Librarian 5

"I think the main thing was trying to work with staff to make them more comfortable providing services outside the library buildings and a lot of people were, you know, very comfortable providing library service in the library but if they went to a community organization they felt quite uncomfortable and they didn't really know how to enjoy promoting the library"- Librarian 9

Confusion regarding why they should engage with these relationship-oriented activities, especially outside of the library, instead of doing the work that they have been taught through library school or through working before the profession started to change, was detected. Through the data, different ideas within the doxa were coded-the professionals described by the interviewees as open to these new activities were contrasted with the professionals who were not open. Working environment was coded as another important factor as the interviewees had witnessed difficulties with doing certain work activities, such as promoting or practicing their services, outside of the library. Through challenging what the professionals had been taught in library school, the new activities seemed to add to the conflict within the doxa. In the sense of controlling work activities, a conflict can be detected among the librarians where some are positive to new or different tasks while others are reluctant.

"It's just like an informal network that has been created among a lot of.. resources" Librarian 7 
"We're the safety net. If they fall through the system, if they get thrown out form one place, or their behaviors are not being good, we catch them. We do work in partnership with a whole range of organizations. Nobody can do everything, we all do our part, we kind of fill gaps. [...]. It's a partnership approach we don't believe that we can do everything ourselves. We also have to meet everybody else's needs, the regular folk who come in who just want to borrow a book. Kind of balances it out." - Librarian 11

The professionals shared how they work with other actors in society to reach their goal - to meet the needs of the community. Since the professionals emphasized the importance of cooperation with other actors in society, their activities were not coded as controlled by the professionals. Professionals who are controlling their work activities according to Abbott, are competing to gain control over their work activities. In other terms, through the lens of Abbott, it could be argued that the lack of control of work activities can be viewed as a part of the deprofessionalization process. The fact that the different ideas-challenging and enabling ones-are coded as opposing forces regarding the professional status, might further validate this theory.

The abstract knowledge of Abbott's theory is again exemplified here as the professionals have acquired the relationship-oriented competencies through work activities and not through their education. And as Abbott noted, that knowledge may oftentimes barely relate to the actual work that the professionals do. What is interesting when the abstract knowledge that the professionals have acquired from LIS school does not align with the work activities of the profession, is that the work activities may intersect with some other occupations or professions. One librarian expressed this concern with the words:

"I spend a lot of time listening to people. I remind myself that I'm not a social worker, while often it feels like the roles overlap. It's different in that I can both offer an ear, library resources, and most importantly a space where people can go and just be." - Librarian 1

One could argue that the professionalization process of librarians becomes ambiguous when other similar occupations operate side by side or even in the same building or through cooperation between the library and that service. The impact of this on the profession was coded as a challenging idea whereas the professional status of the occupation, through controlled activities for instance, was not prioritized.

According to Abbott, when a group of professionals no longer occupy autonomy, or power, over a certain set of work activities, their status as professionals is threatened. The enabling ideas found among the librarians who were more hesitant to the changed, more relationship-oriented work activities, were coded as related to the enabling ideas prioritizing 
the professionalized status of the occupation. The lack of control over work activities was coded as an indicator of deprofessionalization of the public library occupation.

\section{Discussion and conclusion}

The purpose of this study was to explore the impact of community-led work on the (de)professionalization process among public library professionals in Canada and through the analysis of empirical data, a theorization of said impact was explored. It has been acknowledged through previous studies that the profession has changed, and what was found in this study is a theory on how and why this has happened-beyond the effects of external forces such as the digital revolution.

A clear difference between what the librarians were taught in library school and the knowledge they acquired through working, and the skills that they actually used and needed in order to do their job, was coded through the data material. This was conceptualized as abstract knowledge taught in library school, through the lens of Abbott. The empirical analysis indicated that the doxa of the public library professional is being questioned, or opposed, by challenging ideas of the doxa. This theorization adds to the understanding of the process since previous studies only indicated that external factors such as the digital revolution were responsible for this change. The internal conflict that was theorized in this study adds to the understanding of the profession by further exploring how and why it is undergoing these changes.

The conflict theorization was further supported through coding of data that indicated that there is an expertise conflict within the library field where the challenging ideas are opposing autonomy of expertise. Since expertise was found to be not only the core of professions according to Abbott's theory, but also the major cultural value of the public library profession specifically, the challenging ideas regarding the expertise narrative were coded as possible indicators of deprofessionalization, or aims for such process within the field. The expertise conflict was found to be closely related to the education gap which further supported this theory. In conclusion, public library professionals in Canada are facing an internal, collegial conflict between the challenging and the enabling ideas of the doxa as well as through the lens of Abbott's professionalization theory. This conflict might affect the professional status of the occupation in the future if the challenging ideas, concerning for instance relationship-oriented activities, continues to be expressed or embodied by actors within the group.

Interviewing professionals who actively worked with the community led approach, and some who had even worked together, might have interfered with the result of this study as the interviewees offered a specific perspective. However, this study may contribute to a fruitful discussion regarding professionals practicing the community-led approach in relation to the deprofessionalization process. Building on the sensitized theory of this study, an 
exploration of which ideas that dominate-the challenging or enabling ones-may be helpful in order to theorize where a profession is in the process of (de-)professionalization.

\section{Acknowledgements}

I would like to thank Dr. Hultman at Linnaeus University for supervising the original version of this study as well as the two anonymous peer-reviewers and the editor of the Professions and Professionalism journal for their thoughtful and constructive comments. I would also like to extend my thanks to the librarians who enabled this study by generously sharing their experiences.

\section{Article history}

Received: 04 Jun 2020

Accepted: 25 Nov 2020

Published: 14 Dec 2020

\section{References}

Abbott, A.D. (1988). The system of professions: an essay on the division of expert labor. Chicago: Univ. of Chicago Press. https://doi.org/10.7208/chicago/9780226189666.001.0001

Auerbach, Carl F. \& Silverstein, Louise B. (2003). Qualitative data an introduction to coding and analysis. New York: New York University Press

Berthoud, H. \& Finn, R. (2019). Bringing Social Justice behind the Scenes: Transforming the Work of Technical Services. The Serials Librarian, 76 (1-4), 162169. https://doi.org/10.1080/0361526X.2019.1583526

Bourdieu, P. (1977). Outline of a theory of practice. Cambridge: Cambridge University Press. https://doi.org/10.1017/CBO9780511812507

Bourdieu, P. (1986). 'The Forms of Capital'. Handbook of Theory and Research for the Sociology of Capital, edited by J. G. Richardson. New York: Greenwood Press.

Bourdieu, P. (1992). Texter om de intellektuella: en antologi. Stockholm: B. Östlings bokförl. Symposion.

Bourdieu, P. \& Passeron, J. (2008). Reproduktionen: bidrag till en teori om utbildningssystemet. Lund: Arkiv.

Canadian Broadcasting Corporation. (2018, April 4). Good news, bad news as libraries remain open but underfunded, say librarians. CBC. Retrieved March, 15 from https://www.cbc.ca/news/canada/newfoundland-labrador/library-no-closureannouncement-1.4603116

Canadian Library Association. (2012). National Statistical Profile of Canadian Libraries. Retrieved from http://cla.ca/wp-content/uploads/National-Statistics-Profile.pdf 
Carlhed, C. (2011). Fält, habitus och kapital som kompletterande redskap i professionsforskning. Socialvetenskaplig tidskrift, 18 (4), 283-300. Retrieved from https://journals.lub.lu.se/svt/article/view/15723/14206

Charmaz, K. (2006). Constructing grounded theory: a practical guide through qualitative analysis. London: SAGE.

Dalhousie University. (2020). School of Information Management. Retrieved March 16, 2020 from https://www.dal.ca/faculty/management/school-of-informationmanagement/current-students-site/Courses.html

Delica, K. \& Elbeshausen, H. (2013). Socio-cultural innovation through and by public libraries in disadvantaged neighbourhoods in Denmark: concepts and practices. Information Research, 18(3) paper C14. Available at http://InformationR.net/ir/184/colis/paperC14.html

Dey, I. (1999). Grounding grounded theory. San Diego: Academic Press. https://doi.org/10.1016/B978-012214640-4/50011-5

Dorner, D., Campbell-Meier, J,. \& Seto, I. (2017). Making sense of the future of libraries. International Federation of Library Associations and Institutions 43 (4), 321334. https://doi.org/10.1016/B978-012214640-4/50011-5

Government of Canada. (2016). National Occupational Classification. Retrieved March 15, 2020 from https://www.canada.ca/en/employment-socialdevelopment/services/noc.html

Government of Canada. (2020). Librarian in Canada. Job Requirements. Retrieved September 16, 2020 from https://www.jobbank.gc.ca/marketreport/requirements/5263/ca

Hansson, J. \& Wisselgren, P. (red.) (2018). Bibliotekarier i teori och praktik: utbildningsperspektiv på en unik profession. Lund: BTJ förlag.

Harrits Sommer, G. (2016). Being Professional and Being Human. Professional's Sensemaking in the Context of Close and Frequent Interactions with Citizens. Professions and Professionalism, 6 (2). https://doi.org/10.7577/pp.1522

Hyder, E., \& Tissot, C. (2012). 'That's definite discrimination': practice under the umbrella of inclusion. Disability \& Society, 28 (1) https://doi.org/10.1080/09687599.2012.695579

Kirkegaard, S., \& Andersen, D. (2018). Co-production in community mental health services: blurred boundaries or a game of pretend? Sociology of health and wellness, 40 (5), 828-842. https://doi.org/10.1111/1467-9566.12722

Kripps, S., \& Middlemass, C. (2018). What do we mean by Outreach? British Columbia Library Association. 10 (3) Retrieved from https://bclaconnect.ca/perspectives/2018/12/03/what-do-we-mean-by-outreach/

Leemeijer, A., \& Trappenburg, M. (2016). Patient Centered Professionalism? Patient Participation in Mental Health Professional Frameworks. Professions and Professionalism, 6 (2). https://doi.org/10.7577/pp.1474 
Community-led Work and Its Impact on Deprofessionalization

Nichols, L., Knighton, A., Brunisholz, K., Elbel, R., Smith, G., Choberka, A., Belnap, T., Allen, T., Moore, M., Srivastava, R. (2020). Adapting a complex, integrated health and social services intervention in two communities. Health Services Research, 55, 111-112. http://dx.doi.org.proxy.Inu.se/10.1111/1475-6773.13489

Shumaker, D. (2012). The embedded librarian: innovative strategies for taking knowledge where it's needed. Medford, New Jersey: Information Today, Inc.

Tîrziman, E. (2017). The Librarian - A Redefined Profession for the 21st Century. Romanian Journal of Library and Information Science, 13 (4), 101108. https://doi.org/10.26660/rrbsi.2017.13.4.101

Williment, K. (2009). It takes a Community to Create a Library. Partnership: the Canadian Journal of Library and Information Practice and Research; Toronto, 4 (1), 1-11. https://doi.org/10.21083/partnership.v4i1.545

Williment, K., \& Jones-Grant, T. (2012). Asset Mapping at Halifax Public Libraries: A Tool for Beginning to Discover the Library's Role with the Immigrant Community in Halifax. Partnership:the Canadian Journal of Library and Information Practice and Research; Toronto, 7 (1), 1-12. https://doi.org/10.21083/partnership.v7i1.1491

Working Together Project. (2008). Community-Led Libraries Toolkit. Retrieved March 15, 2020 from https://www.vpl.ca/sites/vpl/public/Community-Led-Libraries-Toolkit.pdf 